\title{
UMA BREVE ANÁLISE SOBRE OS LIVROS DIDÁTICOS DESTINADOS À ALFABETIZAÇÃO
}

\author{
YAMASHIRO, Ananda Yumi ${ }^{1}$ \\ MENDONÇA, Onaide Schwartz ${ }^{2}$
}

RESUMO: Este trabalho é parte de uma pesquisa maior que se propôs a analisar uma coletânea de livros didáticos destinados à alfabetização e distribuídos pelo MEC à redes públicas de ensino. A pesquisa tem como objetivo principal identificar possíveis equívocos presentes na estrutura do livro, apontando as incoerências encontradas na metodologia e nas atividades propostas. A análise foi fundamentada na Linguística, na Psicolinguística e em teorias de Magda Soares sobre Alfabetização e Letramento. O levantamento foi feito em livro indicado para o $2^{\circ}$ ano do Ensino Fundamental, da Coletânea Novo bem-me-quer: letramento e alfabetização, Editora do Brasil. Esse estudo mostrou que a quantidade de atividades de Alfabetização é insuficiente para que a criança aprenda a ler e escrever, se comparada às atividades de Letramento, e que estas comparecem de forma descontextualizada. Além dessa análise minuciosa, foi feito um levantamento das atividades presentes no material verificando, segundo a teoria da psicogênese da língua escrita desenvolvida por Ferreiro e Teberosky (1986), se podem ser classificadas como exercícios de nível pré-silábico, silábico ou alfabético. Após a análise foi possível concluir que atividades de nível alfabético são as que comparecem em maior quantidade, o que configura uma incoerência, pois são indicadas a quem já sabe ler e escrever. Assim, conclui-se que os materiais didáticos contribuem para o analfabetismo em nosso país.

Palavras-chave: Alfabetização. Letramento. Livros didáticos.

SUMMARY: This paper is part of a greater research that proposed to analyse a corpus of didactic books destined to literacy and distributed by MEC to the public teaching institutions. The research has as its main objective to identify possible mistakes in the book structure, pointing incoherences found in the methodology and in the proposed activities. The analysis was based on the Linguistic, Psycholinguistic and on theories from Magda Soares about Literacy. The survey was done in 2nd year of Primary School from the corpus "Novo bem-me-quer: letramento e alfabetização, Publishing House do Brazil". This study showed that the amount of literacy activities is insufficient for the kids to learn to read and write if compared to the activities of Letramento and that they are out of a necessary context for learning. Apart from this detailed analysis another survey was made about activities present in the material verifying according to Ferreiro and Teberosky (1986) if the exercises can be classified as pre-syllabical, syllabical or alphabetical. After analysis it was possible to conclude that activities in alphabetical level are the ones that are in the biggest amount, which is incoherent because they are directed to the ones who already know how to read and write. Therefore it is possible to say that the didactic materials contribute to the illiteracy in our country.

Keywords: Literacy. Letramento. Didactic books.

\section{INTRODUÇÃO}

Avaliações recentes vêm apontando dados preocupantes para nosso país. Em 30 de agosto de 2017 foi divulgada a 7ª. Edição do Relatório de Olho nas Metas (2017), pelo "Todos pela Educação" que mostrou, dentre outras informações, que apenas 44,5\% dos alunos do $3^{\circ}$ ano do Ensino Fundamental apresentaram proficiência adequada em Leitura, e apenas 30,1\% em Escrita. Avaliações externas, como o último resultado do PISA (Programa Internacional de Avaliação de Alunos), também têm contribuído para evidenciar essa defasagem, constatando que dentre os países avaliados o Brasil ocupou o $59^{\circ}$ lugar no domínio da leitura e da escrita (MARTINS, 2016).

\footnotetext{
1 Universidade Estadual Paulista "Júlio de Mesquita Filho", FCT/UNESP, Graduação Pedagogia, PIBIC, FCT/UNESP.

${ }^{2}$ Universidade Estadual Paulista “Júlio de Mesquita Filho", FCT/UNESP, Departamento de Educação.
} 
Resultados como esses mostram a precariedade do ensino e as dificuldades que enfrentamos ao lidar com esse processo primordial para a educação e formação dos indivíduos. Sabe-se que o sistema de ensino nunca será eficaz se não for capaz de alfabetizar com competência. Sabe-se também que atualmente, segundo os resultados do Indicador de Alfabetismo Funcional (INAF), 8\% dos brasileiros ainda são analfabetos, 29\% são considerados analfabetos funcionais (pessoas que apresentam muita dificuldade na utilização da leitura e da escrita e de operações matemáticas simples no dia a dia), e apenas 12\% são proficientes em leitura e escrita (AÇÃO EDUCATIVA; INSTITUTO PAULO MONTENEGRO, 2018).

Refletir sobre esses resultados é uma necessidade para se compreender suas principais causas, a fim de se levantar o que precisa ser melhorado para que possamos avançar cada vez mais na qualidade da educação oferecida à escola pública, pensando em estratégias educacionais e reavaliando a efetividade de ações enraizadas na prática docente.

Primeiramente deve-se entender que o fracasso escolar apontado pelas pesquisas é uma decorrência de uma série de fatores que transitam no âmbito educacional, sejam fatores de cunho socioeconômico e político, sejam opções teórico/metodológicas, sejam fatores históricos ou a insuficiência, ou ineficiência, dos cursos de formação de professores. Enfim, são muitos os aspectos a serem considerados que demandam reflexão, compreensão para orientar uma ação.

Dentre os fatores já mencionados acredita-se que a formação docente qualificada seja o diferencial para se conseguir lidar com os diversos problemas que envolvem a educação. Assim, investir nos cursos de licenciatura é investir na melhoria da qualidade do ensino, pois quando os educadores são qualificados a chance de identificarem erros no processo educacional e viabilizarem estratégias para melhorar tal processo é muito maior, pois somente compreendendo o assunto, sabendo aliar teoria à prática, é que se pode ter uma visão mais ampla e completa para propor mudanças e promover um salto qualitativo.

Observando salas de aula de alfabetização é notório que o principal aliado do professor é o livro didático. Aliás, os materiais do PNAIC (Pacto Nacional pela Alfabetização na Idade Certa), 2012, incentivam seu uso classificando-o como excelente recurso a ser seguido (MENDONÇA; KODAMA, 2016).

Acredita-se que este poderia ser um material de apoio à prática docente que apresentasse conteúdos significativos, de onde o professor pudesse escolher atividades para complementar as já elaboradas. No entanto, muitos acabam seguindo à risca o que está contido no livro, sem refletir sobre a sua prática e seu trabalho acaba se tornando limitado. Ainda mais quando o material que chega às escolas carrega em sua estrutura e organização uma série de equívocos prejudiciais à alfabetização.

Para entender melhor o tema faz-se necessário olhar criticamente para o aspecto histórico que envolve alfabetização e letramento. Observando é possível constatar que durante séculos a única metodologia utilizada em larga escala e de forma oficial no Brasil foi a das cartilhas e, segundo dados oficiais, até meados da década de 80 o fracasso em alfabetização era da ordem de $50 \%$.

Foi durante essa década que foi divulgada a teoria da "Psicogênese da língua escrita", de Emilia Ferreiro e Ana Teberosky (1986), mostrando as hipóteses que a criança elabora quando começa a aprender a escrever. Do ponto de vista da Psicolinguística, Ferreiro e Teberosky (1986), descreveram em sua pesquisa o aprendiz formulando hipóteses a respeito da escrita alfabética, percorrendo um caminho que pode ser representado nos níveis pré-silábico, silábico, silábico-alfabético e alfabético. Essa construção segue uma linha regular, organizada em três grandes períodos: $1^{\circ}$ ) o da distinção entre o modo de representação icônica (imagens) ou não icônica (letras, números, sinais); $2^{\circ}$ ) o da construção de formas de diferenciação, com controle progressivo das variações sobre o eixo qualitativo (variedade de grafias) e o eixo quantitativo (quantidade de grafias). Esses dois períodos configuram a fase pré-linguística ou pré- 
silábica; $3^{\circ}$ ) o da fonetização da escrita, quando aparecem suas atribuições de sonorização, iniciado pelo período silábico e terminando no alfabético.

A pesquisa de Ferreiro e Teberosky ganhou força e notoriedade, porém a má interpretação dessa teoria na transposição para a prática trouxe consequências dramáticas ao ensino, pois apesar de ser inovadora e esclarecer muitos pontos obscuros relativos à aprendizagem da escrita, com base nela redes públicas de ensino passaram a propor atividades voltadas apenas para o aspecto social da leitura e da escrita, esquecendo-se totalmente do ensino de conteúdos específicos, indispensáveis ao domínio do sistema alfabético, focando o processo em atividades orais de interpretação de diferentes gêneros textuais, e muitos passaram a se apoiar na premissa de que a criança "aprenderia no seu tempo" e que ela aprenderia através de pistas, descartando a intervenção do professor.

Além disso, é importante ressaltar que Ferreiro e Teberosky são pesquisadoras da área da psicologia e não possuem formação na área do ensino de língua materna. Dessa maneira, nunca estiveram em uma sala de aula com o compromisso de alfabetizar pessoas, mas apenas pesquisando, fato que direciona e limita o olhar das autoras preocupadas em descrever processos de aprendizagem da escrita.

Assim, verifica-se a importância e relevância de se estudar uma das principais causas do fracasso educacional brasileiro, analisando o que se tem sido sugerido pelos livros didáticos e o que se tem feito em sala de aula, visto que é a base do processo de escolarização.

\section{MÉTODO}

Nesse trabalho optou-se por uma pesquisa qualitativa e bibliográfica uma vez que visa estudar aspectos de um determinado conhecimento científico e utilizá-lo como fundamentação na construção de um modelo teórico explicativo de um problema, bem como instrumento auxiliar para a construção e fundamentação de hipóteses.

Assim, trata-se de pesquisa de natureza conceitual e analítica, parte de uma pesquisa mais ampla, que se iniciou por uma busca aprofundada nos estudos realizados em torno do ensino de língua materna, buscando compreender inicialmente as definições de Alfabetização e Letramento.

Nesse sentido, a linguística é quem subsidia com Cagliari que adverte que "Alfabetizar é ensinar a ler e escrever. [...] o segredo da alfabetização é a leitura (decifração)." (CAGLIARI, 1996, p.104), e não a adivinhação sobre o que estaria escrito em um texto a partir do tema, imagens e outros indicadores. Ler, no processo de alfabetização, não é inferir, mas aprender a decifrar sinais gráficos objetivando a compreensão do conteúdo escrito.

Soares concebe Alfabetização como:

[...] tomando-se a palavra em seu sentido próprio como o processo de aquisição da "tecnologia da escrita", isto é, do conjunto de técnicas - procedimentos, habilidades necessárias para a prática da leitura e da escrita: as habilidades de codificação de fonemas em grafemas e de decodificação de grafemas em fonemas, isto é, o domínio do sistema de escrita (alfabético, ortográfico); [...] habilidades de uso de instrumentos de escrita (lápis, caneta, borracha, corretivo, régua, de equipamentos como máquina de escrever, computador...), habilidades de escrever ou ler seguindo a direção correta na página (de cima para baixo, da esquerda para a direita), habilidades de organização espacial do texto na página, habilidades de manipulação correta e adequada dos suportes em que se escreve e nos quais se lê - livro, revista, jornal, papel sob diferentes apresentações e tamanhos (folha de bloco, de almaço, cartaz, tela do computador...). Em síntese: alfabetização é o processo pelo qual se adquire o domínio de um código e das habilidades de utilizá-lo para ler e escrever, ou seja: o domínio da tecnologia - do conjunto de técnicas - para exercer a arte e ciência da escrita. (SOARES, 2003, p.80) 
Já Letramento é definido como:

Ao exercício efetivo e competente da tecnologia da escrita denomina-se letramento, que implica habilidades várias, tais como: capacidade de ler ou escrever para atingir diferentes objetivos - para informar ou informar-se, para interagir com outros, para imergir no imaginário, no estético, para ampliar conhecimentos, para seduzir ou induzir, para divertir-se, para orientar-se, para apoio à catarse....; habilidades de interpretar e produzir diferentes tipos e gêneros de textos; habilidades de orientar-se pelos protocolos de leitura que marcam o texto ou de lançar mão desses protocolos, ao escrever; atitudes de inserção efetiva no mundo da escrita, tendo interesse e prazer em ler e escrever, sabendo utilizar a escrita para encontrar ou fornecer informações e conhecimentos, escrevendo ou lendo de forma diferenciada, segundo as circunstâncias, os objetos, o interlocutor.... (SOARES, 2003, p. 80)

Tais conceitos são de extrema importância para a consecução desse trabalho, para a análise e compreensão do trabalho proposto pelos livros didáticos. Somente cientes dessas concepções que se pode investigar, selecionar e analisar a proporção em que atividades de alfabetização ou de letramento comparecem nos materiais.

Verificar essa proporção é relevante à medida que, para o processo de alfabetização obter sucesso, a quantidade de atividades que objetivam o ensino de conteúdos específicos precisa ser muito maior do que as de letramento, uma vez que é nos primeiros anos da Educação Básica que as crianças deveriam aprender a ler e escrever.

Embora importantes, as atividades de letramento podem ficar em segundo plano nesse período apenas para mostrar a importância da leitura e da escrita na sociedade, pois o aluno terá não só os demais anos do Ensino Fundamental ou Médio, mas o resto de sua vida para exercitar os diferentes usos que se faz da leitura e da escrita.

Nesse sentido, Cagliari também enfatiza que:

Se a escola [...] for clara e objetiva, priorizando a decifração da escrita como segredo da alfabetização e dedicando uma hora por dia às atividades específicas, todos os alunos aprenderão a ler (com mais ou menos dificuldades) em dois ou três meses de trabalho. Esse é o tempo suficiente para que os alunos aprendam a decifrar o que está escrito. Quem sabe fazer isso, está tecnicamente falando, alfabetizado. $O$ resto é o desenvolvimento dessa habilidade e a complementação com conhecimentos que serão aprendidos depois. (CAGLIARI, 1996, p.109-110)

Complementando, Mendonça e Mendonça (2007) afirmam que ao se falar em priorizar a decifração não significa que será realizado um trabalho nos moldes da cartilha, mecânico, de repetição visando à memorização, mas que o professor desenvolverá, além da leitura dos mais diferentes suportes de textos, atividades efetivas de leitura.

Fundamentados em estudos na área da Sociolinguística defendem a alfabetização como um processo discursivo afirmando em sua proposta que:

Os dois primeiros passos, a "codificação" e a "descodificação", representam a fase necessária de exploração das potencialidades mentais do alfabetizando, por meio das linguagens que devem preceder a técnica de ler e escrever, e que instrumentalizam a criança para o desempenho social, tendo acesso ao poder de reivindicação, através das habilidades de discutir, tomar a palavra, expor e superar as formas contemplativas (ingênuas) de compreender o mundo. (MENDONÇA; MENDONÇA, 2007, p. 79-80)

Enfatizam ainda que: 
[...] se o processo de alfabetização, qualquer que seja sua metodologia ou proposta, exclui os passos da "codificação" e da "descodificação", iniciando-se unicamente pela letra ou pela sílaba ou pela palavra, pela frase ou, ainda, mesmo pelo texto, tornar-se-á mecânico, porque tal método ou didática excluem a reflexão sobre a sociedade e o momento histórico em que estão inseridos. (MENDONÇA; MENDONÇA, 2007, p. 80)

Quanto ao ensino de conteúdos específicos, os mesmos autores também defendem que:

O modo mais simples de iniciar a alfabetização é partir do alfabeto maiúsculo de letra de imprensa. Podem ser desenvolvidas atividades de nível pré-silábico, ou seja, o reconhecimento de palavras inteiras, como nomes próprios, em especial o de pessoas e o dos alunos, palavras que compõem outras palavras, reconhecimento de letras iniciais, mediais e finais, identificação, recorte e colagem de letras, enfim atividades que levem o alfabetizando a perceber a associação das letras aos seus respectivos sons, isto é, qual letra representa qual som. (MENDONÇA; MENDONÇA, 2015, p. 23)

Em suas obras Mendonça e Mendonça propõem que hoje se deve alfabetizar letrando, por meio da realização de um trabalho fundamentado no diálogo com base na realidade da criança, como estratégia para motivá-la para a aprendizagem. Recomendam que se "desenvolva diariamente a leitura e a cópia do alfabeto [...], tanto na ordem quanto de trás para frente, do meio para o fim, do meio para o início, a fim de evitar que o aluno apenas memorize a sequência e deixe de fixar a grafia das letras." (MENDONÇA; MENDONÇA, 2015, p. 23)

Enfatizam que as descobertas decorrentes da Psicogênese da língua escrita sejam aproveitadas em benefício tanto do aluno quanto do professor, em forma de atividades que vão ao encontro das necessidades de aprendizagem das crianças. De modo que se a criança estiver classificada no nível présilábico, se apliquem atividades para o seu nível:

a) As Atividades de Nível Pré-silábico objetivam explorar a relação som/grafia a fim de auxiliar o aprendiz a fixar qual letra representa qual som. Esse trabalho pode ser realizado através do reconhecimento de palavras escritas inteiras dentro de suportes de texto (rótulo, embalagens, poesias, letras de músicas etc.) Ex.: O nome MARIANA começa com qual letra? Termina com qual? Dentro deste nome há outras palavras? Quais? Sem alterar a ordem das letras de MARIANA, podemos encontrar: MAR, ARIANA, MARIA, ARI, RI, RIA, IA, MARI e ANA. Uma outra atividade desse nível é aquela em que usamos desenhos como referência para que o aprendiz complete o nome da palavra representada com suas letras iniciais, mediais ou finais, ou ainda, só com vogais ou só com consoantes. (MENDONÇA; MENDONÇA, 2015, p. 17)

Se o aluno estiver no nível silábico:

b) As Atividades de Nível Silábico mostram aos alunos que grafam apenas uma letra para cada sílaba pronunciada (G O para GATO) que, na maioria das vezes, registrar apenas uma letra não será suficiente para escrever o que se quer. Mostram também que unindo sílabas, de modo consciente, formamos palavras com significado. Auxiliam ainda na separação correta das sílabas. Aqui também são usados desenhos para que os alunos completem palavras com sílabas de determinadas famílias silábicas o que, de certa forma, os estimula a ler as sílabas que já estão informadas e descobrir as que estão faltando para que a palavra seja escrita corretamente. (MENDONÇA; MENDONÇA, 2015, p. 17)

E para aqueles que já compreenderem o sistema de base alfabética:

c) As Atividades de Nível Alfabético visam o aprimoramento das habilidades de leitura e de escrita significativas: leitura e escrita das palavras compostas na síntese das sílabas; 
caça-palavras; palavras cruzadas; transposição oral e escrita do dialeto do aluno para o dialeto padrão; interpretação e produção de frases e textos com significado, coesão e coerência. (MENDONÇA; MENDONÇA, 2015, p. 18)

Por outro lado, analisando as orientações do PNAIC (2012) Mendonça e Kodama (2016) observam que:

[...] a ênfase recai sempre sobre o livro didático, as professoras o mencionam como fonte de inspiração e instrumento indispensável ao trabalho em sala e os autores (do PNAIC) repetem o dito por elas, respectivamente "[...] o livro didático é um dos recursos mais ricos que podemos ter em nossas salas de aula" (BRASIL, 2012, p. 38) e [...] os livros didáticos de alfabetização, atualmente, sinalizam como podemos planejar os eixos de ensino do componente curricular Língua Portuguesa, [...] (BRASIL, 2012, p. 8). (MENDONÇA; KODAMA, 2016, p. 2457)

Assim, considerando que documentos federais (distribuídos a todo o país) apoiam e recomendam o uso de livros didáticos para a alfabetização é fundamental que se comece a analisá-los, a fim de se compreender melhor a didática e metodologia que tem influência direta na prática do professor.

É nesse contexto que essa pesquisa se propôs a analisar, à luz da Linguística e da Psicolinguística, o livro didático destinado ao $2^{\circ}$ ano do ensino fundamental da Coleção Novo Bem-me-quer: letramento e alfabetização, para o $1^{\circ}, 2^{\circ}$ e $3^{\circ}$ anos, Editora do Brasil, destinada ao ciclo de alfabetização de três anos, num total de 3 livros, buscando levantar os fundamentos científicos que os subsidiam bem como a pertinência das atividades recomendadas à promoção de uma alfabetização de qualidade que possibilite à criança, ao final de três anos ser alfabetizada, ler, compreender e produzir pequenos textos coesos e coerentes.

Durante essa análise, considerando, ainda, a concepção teórico/prática de Mendonça e Mendonça (2007) pretende-se identificar se nos livros didáticos há metodologia definida, e, respeitando as definições de Soares (2003) para alfabetização e letramento, objetiva-se analisar se as estratégias e/ou atividades presentes nos materiais selecionados promovem o desenvolvimento da alfabetização, do letramento ou da alfabetização e do letramento, que seria o ideal. O predomínio das atividades recomendadas evidenciará isso. Nesse sentido será necessário verificar se eles trabalham:

[...] o que é específico à alfabetização, quando se ensinam as relações entre fonemas e grafemas, mostrando quais e quantas letras são necessárias para se escrever as palavras, quando se apresenta a composição silábica, a separação de sílabas das palavras, a segmentação das palavras dentro de um texto, a ortografia, aspectos referentes à estrutura do texto, o uso de letras maiúsculas e minúsculas etc. (MENDONÇA; MENDONÇA, 2017, p. 137)

Dessa forma, pretende-se investigar se o trabalho promovido pela coletânea, atende aos critérios necessários para promover uma alfabetização eficiente que ajude a formar leitores autônomos e cidadãos críticos, contribuindo para a melhoria do nível do ensino brasileiro e a qualidade de vida das pessoas.

\section{RESULTADO}

O livro didático "Letramento e Alfabetização", Editora do Brasil, Coleção Novo Bem-Me-Quer, para o $2^{\circ}$. Ano, foi idealizado por duas autoras, a primeira tem formação como Mestre em Engenharia de Produção na Área de concentração: Mídia e conhecimento, e atua como Professora de Língua Portuguesa do Ensino Fundamental, Ensino Médio e Ensino Superior. E a segunda autora é Pós-Graduada em Língua e Literatura: Expressões e Comunicação na área de Linguística e Letras, e atua como editora de livros 
didáticos para o Ensino Fundamental e Médio. Em suma, nenhuma das autoras têm experiência em alfabetização, público a que se destina o material.

Esse livro é dividido em 4 Unidades e cada uma contém 3 capítulos. Cada capítulo possui um tema central que fundamenta as leituras e as atividades que serão propostas. Dentro dos capítulos o conteúdo é organizado em Subtítulos como: Nossa Língua, Além do texto, Hora da leitura, Produção, Ortografia e Linguagem oral. Cada um desses subtítulos tem por intuito ensinar algo em específico, sejam questionamentos "Além do texto", referentes a algum conteúdo apresentado na "Hora da leitura", ou os diversos usos da nossa língua materna em: "Nossa língua".

A Unidade 1 inicia o primeiro capítulo abordando aspectos da "História da Escrita" e tem como tema o uso das palavras como meio de comunicação, assim como o uso das cores, dos desenhos e dos gestos, o que é relevante segundo Cagliari (1989), para que a criança saiba de onde surgiu o conhecimento que irá aprender.

Na página 17, dentro do tópico "Nossa língua", o alfabeto é introduzido por um pequeno texto que disserta a respeito do seu surgimento questionando se as crianças já o conhecem. Logo em seguida, nas páginas 18 e 19, diversos alfabetos são apresentados de uma só vez: o alfabeto em letra cursiva e de imprensa, maiúscula e minúscula, porém o número de atividades que seguem para fixação desses conteúdos, fundamentais para se prosseguir com a alfabetização, é ínfimo. Nota-se que esse é o único momento em que o livro introduz o alfabeto em letra de imprensa, supondo que apresentar uma única vez o alfabeto seja suficiente para a fixação pela criança, sendo que não muitas páginas à frente ele aparece já em letra cursiva e propondo atividades.

Constata-se, então, que o material desconsidera o que Mendonça e Mendonça (2013) defendem, de que a sequência mais adequada para a apresentação do alfabeto seja o de imprensa maiúsculo, seguido do minúsculo, sendo que o segundo somente deverá ser apresentado depois que a maioria da sala tiver dominado o primeiro. Assim, somente depois que dominarem os alfabetos de imprensa, conhecendo o valor sonoro das letras, lendo e escrevendo palavras compostas por sílabas simples com autonomia, isto é, compreendido o funcionamento do sistema de escrita alfabética é que se apresentará a letra cursiva. A razão pela qual o alfabeto maiúsculo de imprensa deve ser apresentado primeiro se dá pela facilidade do seu traçado e reconhecimento das letras, já o minúsculo, em razão da necessidade, pois é a letra mais utilizada nos textos veiculados socialmente.

Nas páginas 36 e 37 surgem atividades que tratam de dificuldades ortográficas incompatíveis com o nível do que foi ensinado até então, visto que as crianças evidentemente ainda não teriam conseguido dominar o alfabeto em razão das poucas e insipientes atividades propostas. As atividades são sobre o uso de SS ou Ç, sugerindo que seja possível a um aluno que sequer teve condições de se apropriar do alfabeto, notar a diferença entre o uso de uma ou de outra dificuldade ortográfica, sendo que as sílabas mais simples ainda não foram introduzidas.

Poucas páginas adiante, o livro ainda propõe uma atividade com sílabas complexas como, LH e $\mathrm{RR}$, ao pedir para que formem palavras a partir de palhaço e carroça. Em diversos momentos o livro mostra sílabas descontextualizadas e fora de qualquer ordem que facilite a aprendizagem, misturando sílabas como PRE, DOR, LHO, RAN, NHA, CHA e GE.

Em alguns momentos fica claro que a intenção do livro é ensinar o aluno a reproduzir e a copiar, pois na página 48, no tópico "produção" de texto, pede que a criança registre por escrito uma cantiga de roda. Porém, considerando o que foi ensinado até ali sobre alfabetização, elas se limitariam no máximo a copiar algo e não a criar.

Em muitos momentos ao longo do material pede-se para que as crianças produzam textos (como histórias em quadrinhos, poemas, entrevistas e contos), mas é importante lembrar que essas produções são 
solicitadas antes mesmo de haver um reforço no ensino das letras do alfabeto e após aplicação de um número ínfimo de atividades de nível pré-silábico. Assim, a falta de progressão de dificuldades e regularidade no ensino de conteúdos específicos dificulta sobremaneira a aprendizagem das crianças.

A falta de atividades de nível pré-silábico pode ser observada em diversos momentos no decorrer das páginas, pois exercícios de palavras-cruzadas, de nível alfabético por exigirem escrita de palavras, aparecem antes mesmo de atividades de nível pré-silábico, fato que demonstra falta de conhecimento teórico e prático dos materiais. Um professor experiente sabe que palavras-cruzadas não são adequadas para crianças que sequer conhecem o alfabeto, e que para resolver uma atividade dessas é necessário saber escrever convencionalmente. Do contrário, para que os alunos possam concluir a atividade, a professora terá que escrever as palavras necessárias na lousa.

Na página 72, o exercício 3 coloca em ordem palavras como "mina", "talo", "toca", "taco" e "fica" para que seja acrescentada no meio da palavra a letra $\mathrm{H}$, depois de $\mathrm{C}, \mathrm{L}$ e $\mathrm{N}$, o que é totalmente incoerente, pois apresenta para crianças que não aprenderam o alfabeto, palavras com alto grau de complexidade, de forma descontextualizada e ainda pedem para que acrescentem uma letra aleatória no meio da palavra.



(GIESEN; RODRIGUES, 2014, p. 73)

A Unidade 2 tem como tema principal "O mundo do faz de conta" e o texto que inicia o Capítulo 1 fala sobre fadas e bruxas, tema que já faz parte do imaginário da criança. Porém, as atividades que seguem sobre os textos lidos podem fazer com que a criança deixe de se interessar pela leitura por prazer. São exercícios de interpretação de textos que devem ser respondidos por escrito por quem ainda não sabe ler e escrever:

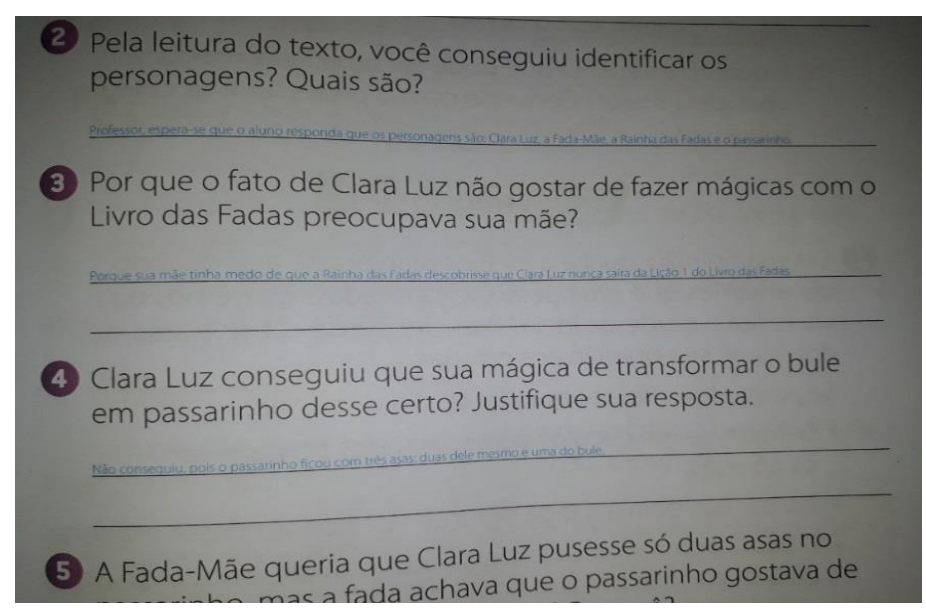

(GIESEN; RODRIGUES, 2014, p. 107) 
Um tópico interessante que poderia aparecer mais vezes é o "Trocando ideias" que geralmente propõe discussões e reflexões em forma de perguntas a serem respondidas, em uma roda de conversa, sobre questões de cidadania, convivência e sociedade, o que Mendonça e Mendonça (2013) propõem como a Codificação e Descodificação em sua proposta para alfabetização.

Entretanto, nos materiais em foco, essa prática é desenvolvida timidamente, com uma ou duas perguntas a serem debatidas e só metade discute questões sociais como os direitos das crianças e questões observáveis a partir do ponto de vista delas. A outra metade se presta a aumentar ainda mais o número de atividades de letramento, com perguntas de interpretação de texto. Aparentemente os materiais, comprados e distribuídos aos milhares pelo país, não têm a preocupação de ensinar as crianças a pensar criticamente.

Algumas páginas adiante, observa-se outra incoerência quanto ao nível de dificuldade das atividades. O material apresenta um exercício composto por uma série de imagens e pede que a primeira letra de cada uma delas seja preenchida para que se forme uma frase. Esta é uma atividade de nível présilábico, mas a incoerência reside no fato de que anteriormente já haviam sido solicitadas até produções de textos de diferentes gêneros, trabalhado letramento e o uso de sílabas mais complexas. Assim, atividades de nível pré-silábico estariam totalmente superadas. Pior do que isso é tentar ensinar gramática a quem não teve a oportunidade de dominar o alfabeto, nem sílabas simples.

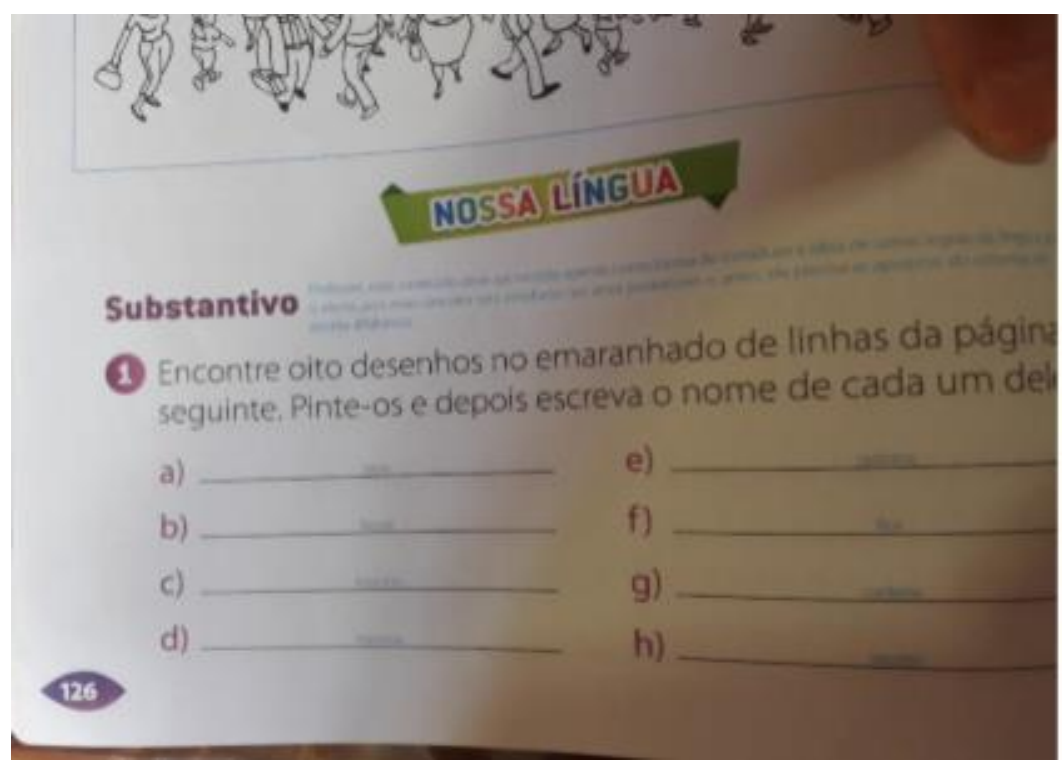

(GIESEN; RODRIGUES, 2014, p. 126)

O fato de o livro ensinar o uso do acento til, de forma separada das outras sílabas, também é questionável. Em seu material didático Mendonça e Mendonça (2015) acrescentam o uso do til já no ensino regular das sílabas, pois essa maneira facilita tanto a compreensão de sua função (nasalização), como sua fixação e uso. Nos materiais em análise, os exercícios usados para trabalhar o til consistem na troca de uma ou duas letras de palavras com a sílaba ÃO por outras, para que formem novas palavras, porém as letras são escolhidas aleatoriamente e formam palavras também aleatórias. 


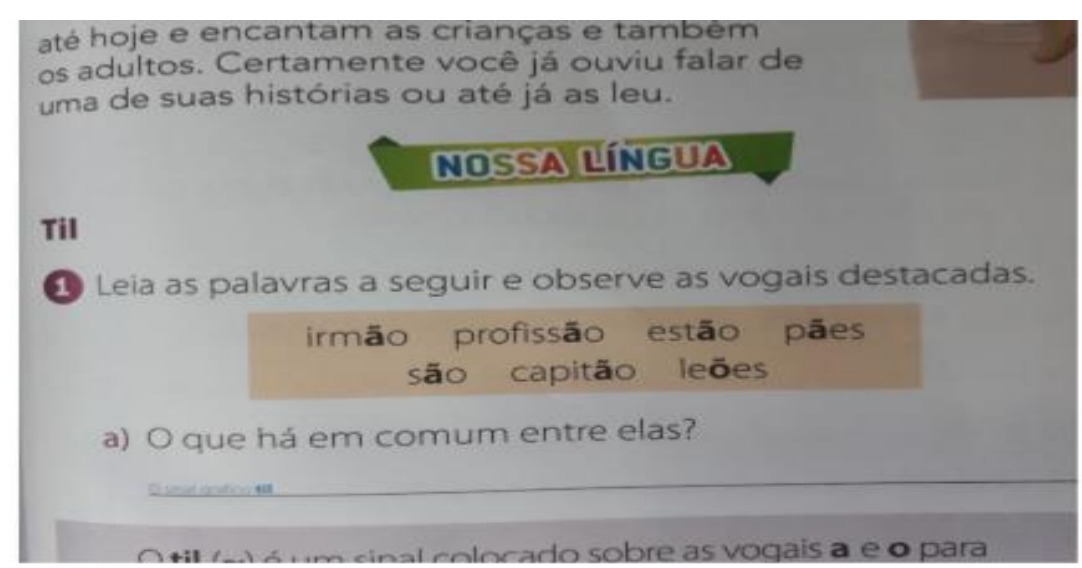

(GIESEN; RODRIGUES, 2014, p. 143)

Ainda, sobre essa aleatoriedade nas escolhas dos exercícios, na página 147 reaparecem as atividades com a letra $\mathrm{H}$, repetindo o que foi pedido anteriormente, são apresentadas palavras para acrescentarem a letra $\mathrm{H}$ no meio para formar: sonho, malha, filha, molha, minha, cacho, bolha, chão, tocha, tacho, telha, chama, ganha, tinha. Mas o pior é quando no exercício 7 da mesma página aparece a frase "A fola estava molada por causa da cuva", frase que não possui sentido algum, e a criança deve colocar a letra $\mathrm{H}$, para que possa atribuir um significado para o que está escrito.

No mesmo capítulo surge um novo tópico: "Conviver fazendo a diferença" que aborda questões sobre direitos humanos universais, os direitos das crianças e dos animais. Sem dúvida essa discussão é urgente, relevante e necessária para a formação integral das pessoas, mas o que chama a atenção é a falta de contextualização. Apesar da extrema necessidade do tema no contexto escolar brasileiro, embora haja um breve diálogo, o assunto é abordado em poucas páginas e rapidamente volta-se aos contos de fadas e ao mundo da fantasia. O material poderia explorar esses conteúdos de outra maneira, trazendo para a realidade da criança e da sociedade, mas opta pela fantasia, o que gera uma contradição.

Ainda, o livro trouxe essas explicações no formato da Declaração dos Direitos da Criança, em seu $2^{\circ}, 6^{\circ}$ e $9^{\circ}$ princípios. Descrevendo, por exemplo, que "a criança necessita de amor e compreensão para o desenvolvimento pleno e harmonioso de sua personalidade [...]", mas, como fica a situação das crianças que não se sentem nem amadas nem protegidas? Essas crianças não se sentiriam ainda mais excluídas? Afinal, esse é um documento que deve ser lido e interpretado pelos adultos que estão à volta delas. É preciso ter cuidado para não gerar mais problemas. Portanto, tudo o que será discutido em sala de aula deve ser pensado e selecionado com cuidado. Poderiam, por exemplo, introduzir essa conversa na unidade que fala sobre infância e brincadeiras, evidenciando o fato de que nem todas as crianças têm acesso aos seus direitos, como deveria ser, aprofundando assim esse diálogo, partindo da realidade das próprias crianças e não de algo voltado para os adultos, como no caso da lei.

Ao final desse capítulo algumas atividades de alfabetização ganharam espaço, mas seguindo as falhas das outras que já tinham sido propostas. Dessa vez aborda-se o uso das letras $\mathrm{M}$ e $\mathrm{N}$ pós vocálicos, e do $\mathrm{M}$ antes de $\mathrm{P}$ e $\mathrm{B}$, seguindo a regra dos outros exercícios que consistem apenas em acrescentar letras no meio de palavras. O uso dessas letras é relacionado ao uso do til com a função da nasalização de sons. Mais uma vez, esses exercícios ocupam um total de 6 páginas dentro de uma unidade cujos capítulos sempre começam com um texto, seguem de muitas perguntas de interpretação desses textos, pedem produções de gêneros textuais e ensinam 
curiosidades da língua e, como sempre, o número de atividades de letramento ultrapassa em muito as atividades de alfabetização.

A Unidade 3 tem como tema principal "brinquedos e brincadeiras" e se configura da mesma maneira que as outras, focando em atividades de letramento e interpretação de texto. A unidade aborda, logo no começo, a variação linguística. O tema possui grande relevância para a formação das crianças permitindo que entendam o modo diferente das pessoas falarem e nomearem objetos, mesmo estando em um país que usa a mesma língua em todo o território, a fim de evitar preconceitos linguísticos. No entanto, apresenta-se uma explicação com apenas 6 linhas sem dar exemplos ou questionar as crianças sobre linguagem coloquial e gírias, o que seria um trabalho muito interessante para se desenvolver no nível alfabético da aprendizagem.

No tópico "Pesquisando" pede-se que as crianças pesquisem textos instrucionais em revistas, jornais, livros e internet, depois devem trocar os textos pesquisados com colegas e ler o que eles trouxeram. Essa é mais uma das atividades que requer leitura por parte do aluno, que ainda não sabe ler, nas quais apenas o professor lerá. No entanto, encontra-se outra incoerência 4 páginas à frente, quando se propõe uma atividade com a apresentação de sílabas formadas a partir da letra C e com QU cujo foco são as vogais. As letras não são apresentadas com clareza, mas no meio de palavras com alto grau de complexidade e sem sistematização desse conteúdo em sílabas (CA/QUI/QUE/CU/CÃO/CO). Esse fato demonstra que os materiais não têm noção sobre quais conteúdos poderiam ser abordados, e em que momento, de modo coerente para facilitar a aprendizagem dos alunos.

A última unidade, "Meu planeta, minha morada", tem como assunto principal a natureza e a relação do homem com ela, trazendo discussões sobre poluição, reflorestamento, meio ambiente, biodiversidade, trabalhando com textos informativos. Entretanto, alguns conceitos importantíssimos para trabalhar com a educação ambiental não aparecem em nenhum momento, faltou abordar discussões sobre a água, sobre a reciclagem e sobre os resíduos sólidos.

Há ainda atividades para preencher lacunas com as palavras que faltam de um texto de acordo com imagens (texto enigmático) e atividades que pedem para que se desembaralhe letras que estão em um quadro para descobrir qual palavra forma. Em dado momento, aparece um código para ser decifrado tirando e acrescentando sílabas nas palavras, de acordo com o que a imagem pede. Lembrando que estas atividades encontram-se ao final do livro e misturando atividades de nível alfabético (texto enigmático) com atividades de nível pré-silábico, mas estão intercaladas com exercícios ortográficos para o uso de $\mathrm{S}$ e $\mathrm{SS}, \mathrm{X}$ e $\mathrm{CH}$, com produção de textos instrucionais, cartazes de conscientização e reportagens, e até mesmo exercícios de coesão textual, nos quais não se explica nem o que é coesão. Ainda, trabalhando o uso de $\mathrm{X}$ e $\mathrm{CH}$, o livro apresenta uma mesma forma e padrão de ensinar, focando muito mais nas letras em si do que nas sílabas ou na palavra.

\section{DISCUSSÃO}

Sabe-se que todo autor de materiais voltados à alfabetização têm a intenção de facilitar a aprendizagem da leitura e da escrita, mas os resultados nem sempre são exitosos. A análise desse livro contribuiu para a identificação de falhas graves do material, mostrando que existem livros didáticos que trazem mais confusão do que clareza às crianças. Atividades são apresentadas de maneira desarticulada e descontextualizada, pois as duas primeiras unidades apresentam temas 
aleatórios que possuem uma certa distância em relação à realidade das crianças, se comparados a outros assuntos que poderiam ter sido abordados. As atividades não seguem uma ordem de progressão de dificuldades, que poderia ir do mais fácil ao mais complexo, e não apresenta sistematização quanto à maneira de ensinar. Desse modo, o que se constatou durante a análise foi uma desordem na apresentação dos conteúdos. Talvez essa conduta reflita os mais diferentes equívocos teórico-metodológicos, já descritos por Mendonça (2007; 2017), decorrentes da divulgação de teoria construtivista em meados da década de 80.

A falta de sistematização e gradação de dificuldades na apresentação dos conteúdos, assim como a priorização de atividades de letramento em detrimento das atividades de alfabetização, revela a falta de compromisso com o ensino por se acreditar, aparentemente, que a escola deve se limitar a dar pistas para que a criança descubra o funcionamento do sistema de escrita, como se aprender a ler e escrever fosse um processo natural que não precisasse ser ensinado e como se a utilização de método na alfabetização fosse algo retrógrado e tradicional.

Ficou evidente, desde os primeiros capítulos, que as atividades de letramento comparecem em número muito superior quando a ênfase deveria estar na alfabetização. Sabe-se que o processo de letramento tem início, mas não tem fim, pois a cada dia há a possibilidade de se aperfeiçoar os conhecimentos de leitura e de escrita. Assim, acredita-se que a ênfase do início do processo de alfabetização deveria recair sobre o ensino/aprendizagem da leitura e da escrita para que o aluno tivesse condições de se apropriar do funcionamento do sistema de escrita alfabética e com isso adquirir desenvoltura na leitura, interpretação e produção de textos. Entretanto, esta análise mostra que, a exemplo do que aconteceu no livro do $1^{\circ}$. Ano também analisado, ocorre o contrário.

É relevante observar que seria compreensível que no $1^{\circ}$. ano se enfatizasse a função social da leitura e da escrita, a fim de estimular a curiosidade das crianças para a aprendizagem, e a aprendizagem da correspondência som/letras do alfabeto. $\mathrm{O} 2^{\circ}$. ano deveria centrar forças no ensino de conteúdos específicos de leitura, a fim de que a criança concluísse o ano alfabetizada, ficando o treino ortográfico das dificuldades da língua (as diferentes representações do som [s]: $\mathrm{s}$, ss, c, ç sc, x; os diferentes usos da letra X; a letra $Z$ com som [s]), a introdução do ensino da pontuação e a ênfase em interpretação e produção de texto para o $3^{\circ}$. ano desse ciclo. Porém, não adianta mencionar tais conteúdos se nem o que é básico não foi trabalhado. Assim, as dificuldades irão se acumular.

Frente às constatações dessa pesquisa, conclui-se que nosso país está longe de resolver a vergonha do fracasso escolar, pois os equívocos que foram divulgados ao longo das últimas três décadas ainda vêm sendo propagados, inclusive pelos materiais oficiais nacionais cujos gestores deveriam estar empenhados em trazer eficiência e dignidade ao ensino brasileiro, pois quem vê os resultados das avaliações externas pode concluir que o brasileiro é incompetente, o que não é verdade, mas está sendo vítima de opções metodológicas equivocadas.

\section{REFERÊNCIAS}

AÇÃO EDUCATIVA; INSTITUTO PAULO MONTENEGRO. INAF Brasil 2018: resultados preliminares. São Paulo: Ação Educativa; IPM, 2018. Disponível em: http://acaoeducativa.org.br/wpcontent/uploads/2018/08/Inaf2018 Relat\%C3\%B3rio-Resultados-Preliminares v08Ago2018.pdf. Acesso em 06 dez. 2018. 
BRASIL. Ministério da Educação. Secretaria de Educação básica. Diretoria de Apoio à Gestão Educacional. PNAIC: Pacto Nacional pela alfabetização na idade certa: ano 1; ano 2; ano 3. Brasília: $\mathrm{MEC} / \mathrm{SEB}, 2012$.

CAGLIARI, L. C. Alfabetização \& Linguística. São Paulo: Scipione, 1989.

CAGLIARI, L. C. Alfabetizando sem o BÁ-BÉ-BI-BÓ-BU. São Paulo: Scipione, 1996.

FERREIRO, E.; TEBEROSKY, A. Psicogênese da língua escrita. Tradução de Diana Myriam Lichtenstein et al. Porto Alegre: Artes Médicas, 1986.

GIESEN, M. R. C.; RODRIGUES, R. de C. Novo bem-me-quer: letramento e alfabetização, $2^{\circ}$ ano: ensino fundamental: anos iniciais - $3^{\mathrm{a}}$. ed. São Paulo, Editora do Brasil, 2014.

MARTINS, L. Brasil está entre os piores do mundo em avaliação da educação. 06/12/2016. Estadão. Disponível em: https://educacao.estadao.com.br/noticias/geral,brasil-esta-entre-os-piores-do-mundo-emavaliacao-de-educacao. Acesso 29 set. 2018.

MENDONÇA, O. S.; MENDONÇA, O. C. Alfabetização - método sociolinguístico: consciência social, silábica e alfabética em Paulo Freire. São Paulo: Cortez, 2007.

MENDONÇA, O. S.; MENDONÇA, O. C. Alfabetizar as crianças na idade certa com Paulo Freire e Emília Ferreiro: práticas socioconstrutivistas. São Paulo: Paulus, 2015.

MENDONÇA, O. S.; MENDONÇA, O. C. Contribuições da psicogênese da língua escrita para a alfabetização: interpretação e consequências: fundamentos, práticas e resultados. In: INFORSATO, E. C.; COELHO, S. M. Anos Iniciais do Ensino Fundamental. São Paulo: UNESP/UNIVESP, 2017. Cap. 10, p. $129-150$.

MENDONÇA, O. S.; KODAMA, M. R. de O. Alfabetização: por que a criança não aprende a ler e escrever? Rev. Ibero Americana em Educação, Araraquara, v.11, n. esp. 4. p. 2448-2464, dez. 2016.

Relatório De Olho nas Metas 2015-16. 30 de agosto de 2017. TODOS PELA EDUCAÇÃ̃o. Disponível em: http://www.todospelaeducacao.org.br/reportagens-tpe/43464/todos-pela-educacao-apresenta-a-7edicao-do-relatorio-de-olho-nas-metas/ Acesso em 20 mar. 2018.

SOARES, M. Letramento e escolarização. In: Unidades de Formação - Alfabetização. São Paulo: UNESP, p. 79-98, 2003. 